\title{
Gastric Cancer Pathology and Underlying Molecular Mechanisms
}

\author{
Heike I. Grabsch ${ }^{a, b}$ Patrick Tan ${ }^{c-f}$ \\ ${ }^{a}$ Leeds Institute of Cancer and Pathology, University of Leeds, and ${ }^{b}$ Department of Histopathology and Molecular \\ Pathology, St James's Institute of Oncology, Leeds Teaching Hospitals NHS Trust, Leeds, UK; 'C Cancer and Stem \\ Cell Biology, Duke-NUS Graduate Medical School, dCancer Science Institute of Singapore, Yong Loo Lin School of \\ Medicine, National University of Singapore, ${ }^{\mathrm{e}}$ Genome Institute of Singapore, and ${ }^{\mathrm{f} C e l l u l a r}$ and Molecular Research, \\ National Cancer Centre, Singapore, Singapore
}

\section{Key Words}

Gastric cancer · Genetic alterations · Pathology

\begin{abstract}
The development of gastric adenocarcinoma is a complex multistep process involving multiple genetic alterations. Based on pathology, four different macroscopic types and at least two major histological types, intestinal and diffuse, have been described. Most gastric cancer (GC) show genetic instability, either microsatellite instability or chromosomal instability, which is considered an early event in gastric carcinogenesis. Molecular studies of alterations of single genes have provided evidence that intestinal and diffuse type GC evolve via different genetic pathways. Recent results from high-throughput whole-genome expression or copy number studies have demonstrated extensive genetic diversity between cases and within individual GC. Sets of commonly up- or downregulated microRNAs have been identified in GC and might be useful in the near future to identify pathways of GC progression. Results from detailed molecular and/or pathological GC studies, although promising, still have limited clinical utility in predicting survival and stratifying GC patients for appropriate treatment.
\end{abstract}

Copyright $\odot 2013$ S. Karger AG, Basel

\section{KARGER}

(c) 2013 S. Karger AG, Base

0253-4886/13/0302-0150\$38.00/0

E-Mail karger@karger.com

www.karger.com/dsu

\section{Introduction}

Gastric cancer (GC) remains one of the most common cancers and second leading cause of cancer death in the world, accounting for 1,000,000 new cases and 738,000 deaths per year. Although the incidence and mortality rates have been declining steadily, the absolute number of new cases is actually increasing due to the aging population.

Approximately 95\% of GC are adenocarcinomas which have been classified by anatomic site as cardia/ proximal cancers or noncardia/distal cancers in epidemiological studies [1] and by histological phenotype as intestinal type, diffuse type and mixed/unclassifiable according to Lauren's classification [2]. Patients with proximal GC have a poorer survival independent of TNM stage [3]. Cancers in the distal stomach are more frequently seen in the elderly male population, are related to Helicobacter pylori infection, and are usually of intestinal type histology. More recently, several molecular classifications of GC have been proposed based on the analysis of whole-genome gene expression studies and/or gene copy number studies [4-8].

The decline in GC incidence has been attributed to a decrease in the number of intestinal type GC and the number of distal GC, and correlated with a parallel decrease in the prevalence of $H$. pylori infection [9]. Never- 
theless, intestinal type GC still predominates in high-risk areas such as Asia, Eastern Europe, and South America, whereas diffuse type GC has a much more uniform geographic distribution and increasing incidence [10]. Diffuse type GC is more common in females and younger patients, but studies have failed to demonstrate that the decline in intestinal type cancers is related to a shift in the male:female incidence ratio or related to changes in the age of the population (for review, see [11]).

\section{Pathology of Gastric Cancer}

\section{Macroscopy}

In order to optimize communication between surgeons, endoscopists, radiologists, and pathologists, and facilitate the appropriate treatment strategy, the macroscopic appearance of GC has been described using the Borrmann classification for advanced GC (type I: polypoid with broad base and no ulceration; type II: ulcerating with sharp margin and elevated borders; type III: ulcerating and diffusely infiltrating into surrounding wall, and type IV: diffusely infiltrating mostly without ulceration [12]) and the Paris classification for early GC (type 0-I: polypoid growth (subcategorized into 0-Ip for pedunculated growth and 0-Is for sessile growth); type 0-II: nonpolypoid growth (subcategorized into type 0-IIa for slightly elevated growth, type 0 -IIb for flat growth, and type 0 -IIc for slightly depressed growth), and type 0 -III: for excavated growth [13]).

A relationship between the macroscopic growth pattern (Borrmann type), tumor location within the stomach, gender, age at diagnosis, histological subtype, and survival has been described. Polypoid and ulcerated tumors with elevated edges (Borrmann types I and II) are most commonly of intestinal type and located in the antrum of the elderly male, whereas diffusely infiltrating tumors (Borrmann types III and IV) are most commonly diffuse type GC in the proximal stomach in middle-aged females [14]. The Borrmann type has been shown to be an independent prognostic factor in GC, with patients with type IV GC having the poorest survival [15].

\section{Microscopy}

GC is histologically very heterogeneous: more than $50 \%$ of GC are pluriform and the variability of the histological appearance has been shown to increase with in- creasing depth of infiltration into the wall [14]. As a result of this morphological diversity, a number of different classification systems have been advocated: the classifications according to Lauren [2], Ming [16], the World Health Organization (WHO) [17], Nakamura et al. [18], Mulligan [19], Goseki et al. [20], and Carneiro [21], as well as the Japanese classification [22].

The most commonly used classifications are those of Lauren [2] and the WHO [17]. Lauren's intestinal type GC shows a predominance of glandular epithelium with cells similar to intestinal columnar cells, good cellular cohesion and a pushing margin at the invasive edge. Lauren's diffuse type GC is composed of scattered poorly cohesive cells or small clusters of cells with little or no gland formation and a diffuse infiltrative margin. Tumor cells may contain mucus and can have a signet ring cell appearance. GC that consists of 50\% diffuse and 50\% intestinal type, solid type cancers, and others that cannot be classified as diffuse or intestinal are called indeterminate, unclassifiable, or mixed. Diffuse and intestinal type GC have different clinicopathological characteristics (reviewed in [14]): intestinal type GC grows in a more shallow fashion, is significantly larger in size before breaching the serosal surface, and has a higher incidence of blood vessel invasion and liver and lung metastases, whereas diffuse type GC spreads more commonly via the lymphatics to the pleura and peritoneum. The male:female ratio is 2.3 for intestinal type GC and 1.5 for diffuse type GC. Patients with intestinal type GC are at a median 7 years older at diagnosis and the background stomach shows multifocal atrophic gastritis and intestinal metaplasia.

Apart from the classification based on tumor morphology, GC can be classified on the basis of mucin stainings into $\mathrm{G}$ type (gastric phenotype; positive for antibodies against MUC5AC, MUC6, HGM, and TFF1), I type (intestinal phenotype; positive for MUC2, CDX2, and CD10), GI type (mixed profile), and N (null type) [23].

More recently, three subtypes of GC have been proposed based on tumor location, histological features, and clinical course [6]: (1) proximal nondiffuse GC which is located in the gastric cardia and shows evidence of glandular dysplasia and chronic inflammation without atrophy; (2) diffuse GC which can be located anywhere in the stomach, has no glandular component, and no evidence of inflammation or atrophy, and (3) distal nondiffuse GC which is an intestinal type GC with chronic gastritis, atrophy, and intestinal metaplasia in the background. 


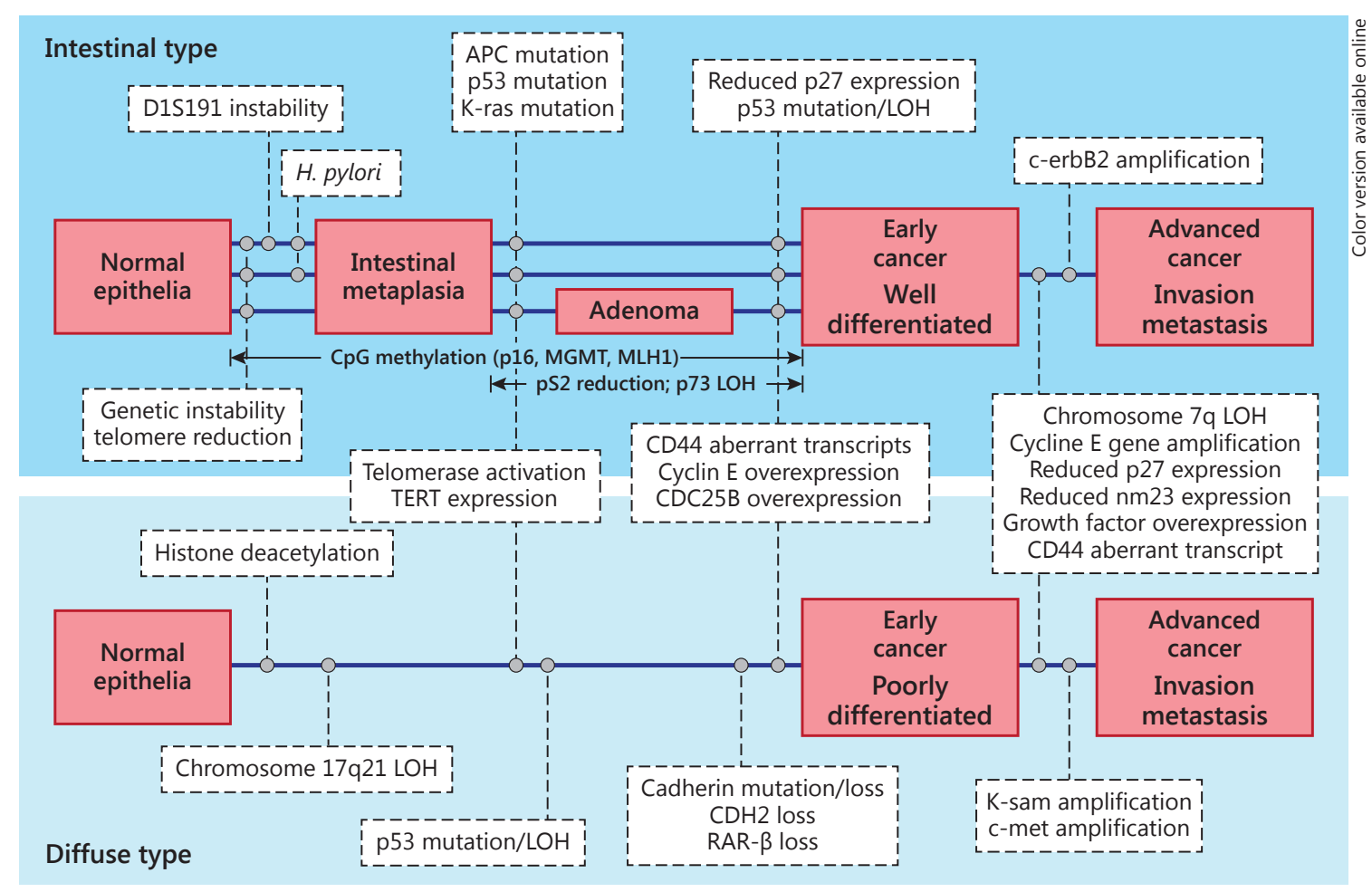

Fig. 1. The Yasui/Tahara multistep model of molecular pathogenesis of gastric cancer (reproduced with permission from [94]).

\section{Molecular Mechanisms of Gastric Carcinogenesis}

GC is thought to result from a combination of environmental factors such as $H$. pylori infection and diet and the accumulation of generalized as well as specific genetic alterations. A model summarizing the sequence of molecular events for intestinal type and diffuse type GC has been proposed by Tahara and Yasui (fig. 1) [24] This model incorporates the previously proposed 'Correa model' of GC development via an intestinal metaplasia-adenoma-carcinoma sequence which was based on epidemiological, pathological, and clinical observations as one possible strand in the development of intestinal type GC [25]. As one can see from this model, there are certain alterations which are common to both major histological subtypes of GC, such as p53 mutation, cyclin E overexpression/amplification, or aberrant CD44 transcripts. Others like KRAS mutations, $C D H 1$ mutations, and amplifications of HER2, FGFR2, and MET appear to be more 'specific' for one of the histological subtypes.

\section{Genetic Predisposition}

Ten to $15 \%$ of GC show familial clustering [26], but only $1-3 \%$ of GC are related to identified inherited GC predisposition syndromes [27] such as hereditary diffuse GC, hereditary nonpolyposis colon cancer (Lynch syndrome), familial adenomatous polyposis, Peutz-Jeghers syndrome, LiFraumeni syndrome, or familial breast and ovarian cancer.

One of the defining criteria of hereditary diffuse GC is the presence of a $C D H 1$ (E-cadherin) germline mutation [28]. $\mathrm{CDH} 1$ mutations have only been found in hereditary and sporadic diffuse type GC, but not in intestinal type GC. In contrast, GC in patients with germline mutations in one of the DNA mismatch repair genes (hereditary nonpolyposis colon cancer patients) show intestinal type morphology in $79 \%$ of patients [29].

\section{Genomic Instability}

One of the hallmarks of cancer development is destabilization of the genome, also referred to as 'genetic or genomic instability' [30], which can be found in all dif- 
ferent histological subtypes of GC and is believed to be one of the initial steps of gastric carcinogenesis [31]. Three phenotypes of instability have been identified in GC: (1) microsatellite instability (MSI) due to a defect in the DNA mismatch repair pathway [32]; (2) chromosomal instability (CIN) which is characterized by an increased rate of loss or gain of whole chromosomes or parts of chromosomes during cell division due to mutations in genes controlling the segregation of genetic material during mitosis [30], and (3) the cytosine and guanine $(\mathrm{CpG})$ island methylator phenotype (CIMP) [33, 34].

Consistent with the hypothesis that genomic instability is an initial step in gastric carcinogenesis, DNA aneuploidy has been observed in intramucosal GC less than $5 \mathrm{~mm}$ in diameter [59] as well as in early GC [60]. Similarly, copy number alterations have been found in GC precursor lesions [61, 62]; MSI has been identified in intestinal metaplasia $[63,64]$, gastric adenoma [64], and early GC [65], and CIMP is present in $15 \%$ of intestinal metaplasia and $50 \%$ of adenomas [34].

\section{Microsatellite Instability}

Patients with a deficiency or inactivation of one of the DNA mismatch repair proteins MLH1, MSH2, MSH6, or PMS2 in their cancer are unable to repair naturally occurring DNA replication errors due to slippage of the DNA polymerase during DNA synthesis, leading to the appearance of new alleles not present in the normal DNA - the so-called 'MSI phenotype' or 'replication error phenotype'. MSI can lead to subsequent genetic changes, usually frameshift mutations, in hundreds to thousands of genes which have also been demonstrated in GC [35].

The reported frequency of MSI in GC varies between 15 and $38 \%$, strongly depending on the number of loci investigated $[36,37]$. Overall, the frequency of MSI was higher in intestinal type GC, older age females, and distal GC $[38,39]$. MSI GC were more often classified as Borrmann type I or II and showed microscopically a high number of tumor-infiltrating lymphocytes. Patients with MSI GC were usually diagnosed at an earlier disease stage and some but not all studies showed a relationship of MSI and improved survival [40]. In most GC, MSI was due to hypermethylation of the MLH1 promoter [41].

\section{Chromosomal Instability}

Chromosomal instability (CIN), defined as an increased rate of loss or gain of whole chromosomes or large portions of chromosomes, can lead to oncogene activation or tumor suppressor gene inactivation. Although $\mathrm{CIN}$ is defined as a rate, e.g. a dynamic process, CIN can only be assessed with surrogate (static) markers such as DNA cytometry to determine changes in nuclear DNA content (DNA ploidy), comparative genomic hybridization $(\mathrm{CGH})$, or other methods such as fluorescence in situ hybridization to determine gene copy number or loss of heterozygosity $(\mathrm{LOH})$ studies.

DNA aneuploidy in GC has been reported in 27-100\% of cases with prominent heterogeneity within the same cancer. Conflicting results have been reported regarding the relationship between DNA ploidy status, clinicopathological variables (depth of invasion, lymph node status, histological subtypes), and patient survival (for review see [42]).

Whole genome array CGH studies have identified complex recurrent patterns of copy number gains and losses in GC (for review see [43]). Specific DNA copy number changes have been found to be related to histological subtypes [44-46], lymph node status [46-48], depth of tumor invasion [47], tumor location [44], age [49], ethnicity [50], and patient survival [51, 52]. Most of the published studies have used CGH as a method to identify candidate genes which may play a role in gastric carcinogenesis or can potentially be used for predicting patient prognosis $[46,52,53]$. It needs to be recognized that CGH can only measure DNA copy number aberrations, thus balanced structural aberrations, translocations, inversions, insertions, and fusions cannot be detected with this method.

$\mathrm{LOH}$ is also a marker of CIN and the presence of $\mathrm{LOH}$ at specific chromosomal regions can facilitate the identification of tumor suppressor genes. Several $\mathrm{LOH}$ studies have been performed in GC demonstrating that the extent of LOH on certain chromosomes, such as chromosome $6 \mathrm{q}, 8 \mathrm{p}, 16 \mathrm{q}$, and $22 \mathrm{q}$, appears to be related to patient prognosis $[54,55]$.

\section{CpG Island Methylator Phenotype}

Aberrant methylation of $\mathrm{CpG}$-rich regions results in silencing of genes and is a common phenomenon in cancer. CpG island methylation is increased in the normal mucosa of patients with chronic inflammatory conditions such as $H$. pylori and Epstein-Barr virus infection and has been considered a precursor lesion for the development of GC [56].

Inactivation of tumor suppressor genes by methylation may result in uncontrolled cellular growth, vascular invasion, and metastasis. CIMP is characterized by concordant methylation of multiple genes and has been described in up to $50 \%$ of GC $[33,57]$. Data analyzing the relationship between CIMP and clinicopathological data 
is still limited in GC. It has been suggested that CIMP is more frequently seen in proximal and diffuse type GC [58], whereas the relationship between CIMP and prognosis is still controversial $[33,58]$.

\section{Selected Single Gene Alterations}

Many genes have been analyzed in an attempt to better understand gastric carcinogenesis as well as GC progression and to discover biomarkers for diagnosis, prognosis prediction and potential drug targets. A summary of selected genes is presented below.

The oncogene $M E T$ encodes a transmembrane tyrosine kinase receptor that binds hepatocyte growth factor and is amplified at higher frequency in diffuse type GC compared to intestinal type GC (39 vs. 19\% [66]). Overexpression of MET has been related to tumor stage and clinical outcome [67]. With the advent of MET inhibitors, the interest in this molecule had a revival, and a very recent large study conducted in Korea demonstrated that MET was amplified in $21 \%$ of GC and related to poor patient survival [68].

Abnormalities of the fibroblast growth factor system tend to be more commonly associated with diffuse type GC, whereas intestinal type GC harbor more frequently abnormalities in the genes/proteins related to the epidermal growth factor system.

$K-S A M$ [now called fibroblast growth factor receptor 2 (FGFR2)] amplification has been detected in diffuse type GC and only rarely in intestinal type GC. FGFR2 overexpression proved to be an independent predictive marker of poor survival in one GC study [69], but was not related to prognosis in another GC study [70]. HST-1 (now called fibroblast growth factor 4) was the first oncogene identified in GC in 1986 [71] and was found to be amplified exclusively in metastatic GC [72]. The expression of basic fibroblast growth factor and FGFR was increased more commonly in undifferentiated and scirrhous GC and was associated with larger tumor size and higher stage [73].

Human epidermal growth factor receptor 2 (HER2), also known as c-erbB2 or HER2/neu, is a tyrosine kinase which does not have any known ligands. HER2 amplification and overexpression has been reported in up to $27 \%$ of intestinal type GC and only rarely in diffuse type GC [74]. The relationship between HER2 expression/HER2 amplification and GC patient survival remains controversial (for recent studies see $[75,76]$ ). HER2 positivity predicted response to trastuzumab in the recent TOGA trial [77].
KRAS mutations on codons 12 and 13 have been found on average in $5 \%$ of GC and were preferentially present in well-differentiated intestinal type GC [78, 79]. In contrast to colorectal cancer, KRAS mutations in GC are more frequently seen in GC with MSI $[29,79,80]$.

p53 is a nuclear protein involved in cell cycle control, DNA repair, and programmed cell death. p53 is frequently inactivated in GC by LOH or mutations. $p 53$ mutations have been identified in $60 \%$ of GC with approximately equal frequency in different histological subtypes, which makes it the most frequently mutated gene in GC [81]. p53 mutations have also been identified in GC adenomas [82] and intestinal metaplasia [83]. The prognostic impact of $p 53$ mutations, $\mathrm{LOH}$, and p53 expression in GC is still controversial.

APC is a multidomain protein with binding sites for numerous proteins including Wnt signaling pathway components $\beta$-catenin and axin and cytoskeletal regulators EB1. APC plays a major role in cell adhesion, cell migration, spindle formation, and chromosome segregation. $A P C$ mutations are the second most frequent mutations in GC and have been observed in $30-40 \%$ of well- and moderately differentiated intestinal type GC and in less than $2 \%$ of diffuse type GC [84]. LOH at the $A P C$ locus was associated with intestinal type GC [29]. $A P C$ mutations have also been described in adenomas of the stomach [85] and intestinal metaplasia [85], indicating that they occur during early stages of GC development.

RUNX3 is a member of the runt domain-containing family of transcription factors regulating apoptosis, cell growth, and angiogenesis. RUNX3 is expressed in up to $50 \%$ of GC and has been associated with better patient prognosis [86]. Inactivation of RUNX3 in GC is most frequently due to hypermethylation of the promoter region [87].

\section{Whole Genome Studies}

Major efforts have been made recently using modern high-throughput molecular methods with the aim to complement traditional histopathological diagnosis and prognosis prediction in GC and to contribute to a better understanding of the biology of GC at a molecular level.

Zang et al. [88] sequenced the exomes of 15 gastric adenocarcinomas and found on average 50 mutations/ case, mostly involving genes involved in cell adhesion and chromatin remodeling. Furthermore, mutations in 
two new putative tumor suppressor genes, FAT4 and ARID1A, were described in GC for the first time.

Whole genome expression profiling in GC can be challenging due to the relative large number of inflammatory cells and presence of stromal cells. To eliminate the interference of 'contaminating' cell populations with the profiling of cancer cells, Tan et al. [7] investigated the gene expression profile in a large number of GC cell lines and identified two major genomic subtypes which were then applied in primary GC tissue samples. Interestingly, concordance of the genotypic classification with the phenotypic classification according to Lauren was only seen in $64 \%$ of GC, suggesting that unsupervised gene expression studies can lead to the identification of distinct subtypes of GC which are currently not recognizable using classic morphological methods. Furthermore, the study showed that it is the genotype-based classification which is of prognostic value and can predict response to certain types of chemotherapy in GC cell lines.

On the other hand, a whole genome expression study using RNA extracted from GC tissue sections demonstrated that a high level of expression of stroma-related genes is significantly related to poor patient prognosis [89]. Interestingly, in contrast to the study which identified two genotypes which were only partly concordant with the phenotype, this study showed a good correlation between the genotype, e.g. high expression of stroma genes, and the phenotype, e.g. high amount of stroma measured morphometrically on routine histology slides, and prognostic value of both.

Two very recent genome-wide copy number profiling studies using high-resolution SNP arrays have been able to demonstrate the power of modern molecular technology in identifying new clinically relevant subtypes of GC $[8,90]$. Both studies identified independently that up to $37 \%$ of GC show high amplifications of genes encoding druggable tyrosine kinase receptor proteins such as FGFR2, HER2, EGFR, and MET. Furthermore, these gene amplifications were almost always exclusive emphasizing the molecular heterogeneity of GC and the need to develop new treatment strategies based on molecular profiles.

\section{MicroRNA}

MicroRNAs (miRNAs) are small non-coding RNAs which regulate gene expression at the posttranscriptional level. Recent evidence indicates that miRNAs are involved in many important biological processes such as

proliferation, differentiation, angiogenesis, and immune response. It is therefore not surprising that more and more reports are published emphasizing the involvement of miRNAs in malignancy (for review see [91]). Several miRNAs have been shown to be related to certain GC subtypes, GC progression, and potential treatment targets, albeit with inconsistent results probably related to small sample sizes [92, 93].

\section{Conclusion}

GC is a heterogeneous and complex disease which has traditionally been subdivided based on epidemiological, macroscopical, and histological classifications to understand cancer biology and determine patient prognosis.

Alterations in multiple single genes and complex copy number and gene expression profiles have been identified in GC over the last two decades. However, their significance in gastric carcinogenesis, tumor progression, and patient survival remains to be determined. Definitive clinical utility has only been shown for two genes in GC so far: $C D H 1$ germline mutations to identify persons at high risk of developing hereditary GC who need to be entered into an appropriate surveillance program, and HER2 amplification/overexpression as a predictor of response to trastuzumab.

Molecular classifications have enabled us to detect multiple parallel occurring molecular alterations in GC, and further studies are needed to unravel their significance for gastric carcinogenesis. It is likely that the response to chemotherapy and patient prognosis will depend on the molecular tumor type; therefore, the identification of a robust and clinically relevant genotype-based histopathological classification of GC is an essential strategy to individualize and guide treatment decisions for GC patients in the near future.

References
$>1$ Crew KD, Neugut AI: Epidemiology of gastric cancer. World J Gastroenterol 2006;12:354362 .

2 Lauren P: The two histological main types of gastric carcinoma: diffuse and so called intestinal-type carcinoma. Acta Pathol Microbiol Scand 1965;64:31-49.

3 Pacelli F, Papa V, Caprino P, Sgadari A, Bossola M, Doglietto GB: Proximal compared with distal gastric cancer: multivariate analysis of prognostic factors. Am Surg 2001;67: 697-703. 
-4 Tay ST, Leong SH, Yu K, Aggarwal A, Tan SY, Lee $\mathrm{CH}$, et al: A combined comparative genomic hybridization and expression microarray analysis of gastric cancer reveals novel molecular subtypes. Cancer Res 2003;63: 3309-3316.

5 Ooi CH, Ivanova T, Wu J, Lee M, Tan IB, Tao $\mathrm{J}$, et al: Oncogenic pathway combinations predict clinical prognosis in gastric cancer. PLoS Genet 2009;5:e1000676.

-6 Shah MA, Khanin R, Tang L, Janjigian YY, Klimstra DS, Gerdes H, et al: Molecular classification of gastric cancer: a new paradigm. Clin Cancer Res 2011;17:2693-2701.

7 Tan IB, Ivanova T, Lim KH, Ong CW, Deng $\mathrm{N}$, Lee J, et al: Intrinsic subtypes of gastric cancer, based on gene expression pattern, predict survival and respond differently to chemotherapy. Gastroenterol 2011;141:476-485, 485.e1-11.

$>8$ Deng N, Goh LK, Wang H, Das K, Tao J, Tan IB, et al: A comprehensive survey of genomic alterations in gastric cancer reveals systematic patterns of molecular exclusivity and co-occurrence among distinct therapeutic targets. Gut 2012;61:673-684.

-9 Konturek PC, Konturek SJ, Brzozowski T: Gastric cancer and Helicobacter pylori infection. J Physiol Pharmacol 2006;57(suppl 3):51-65.

$\checkmark 10$ Henson DE, Dittus C, Younes M, Nguyen H, Albores-Saavedra J: Differential trends in the intestinal and diffuse types of gastric carcinoma in the United States, 1973-2000: increase in the signet ring cell type. Arch Pathol Lab Med 2004;128:765-770.

$\checkmark 11$ Lauren PA, Nevalainen TJ: Epidemiology of intestinal and diffuse types of gastric carcinoma a time-trend study in Finland with comparison between studies from high- and lowrisk areas. Cancer 1993;71:2926-2933.

12 Borrmann R: Geschwulste des Magens und Duodenums; in Henke F, Lubarsch O (eds): Handbuch der Speziellen Pathologischen Anatomie und Histologie. Berlin, Springer, 1926, pp 864-871.

13 The Paris endoscopic classification of superficial neoplastic lesions: esophagus, stomach, and colon: November 30 to December 1, 2002. Gastrointest Endosc 2003;58:S3-S43.

14 Nishi M, Ichikawa H, Nakajima T: Gastric Cancer. Santa Clara, Springer/Telos, 1994.

15 Li C, Oh SJ, Kim S, Hyung WJ, Yan M, Zhu $\mathrm{ZG}$, et al: Macroscopic Borrmann type as a simple prognostic indicator in patients with advanced gastric cancer. Oncology 2009;77: 197-204.

16 Ming SC: Gastric carcinoma - a pathological classification. Cancer 1977;39:2475-2485.

17 WHO Classification of Tumours of the Digestive System, ed 4. Lyon, IARC, 2010.

18 Nakamura K, Sugano H, Takagi K: Carcinoma of the stomach in incipient phase: its histogenesis and histological appearances. Gann 1968;59:251-258.
9 Mulligan RM: Histogenesis and biologic behavior of gastric carcinoma. Pathol Annu 1972;7:349-415.

20 Goseki N, Takizawa T, Koike M: Differences in the mode of the extension of gastric cancer classified by histological type: new histological classification of gastric carcinoma. Gut 1992;33:606-612.

21 Carneiro F: Classification of gastric carcinomas. Curr Diagn Pathol 1997;4:51-59.

22 Japanese Gastric Cancer Association: Japanese classification of gastric carcinoma: 3rd English edition. Gastric Cancer 2011;14:101112.

23 Machado JC, Nogueira AM, Carneiro F, Reis CA, Sobrinho-Simoes M: Gastric carcinoma exhibits distinct types of cell differentiation: an immunohistochemical study of trefoil peptides (TFF1 and TFF2) and mucins (MUC1, MUC2, MUC5AC, and MUC6). J Pathol 2000;190:437-443.

24 Yasui W, Oue N, Aung PP, Matsumura S, Shutoh M, Nakayama H: Molecular-pathological prognostic factors of gastric cancer: a review. Gastric Cancer 2005;8:86-94.

25 Correa P: A human model of gastric carcinogenesis. Cancer Res 1988;48:3554-3560.

26 Zanghieri G, Gregorio CD, Sacchetti C, Fante R, Sassatelli R, Cannizzo G, et al: Familial occurrence of gastric cancer in the 2-year experience of a population-based registry. Cancer 1990;66:2047-2051.

27 Palli D, Galli M, Caporaso NE, Cipriani F, Decarli A, Saieva C, et al: Family history and risk of stomach cancer in Italy. Cancer Epidemiol Biomarkers Prev 1994;3:15-18.

28 Fitzgerald RC, Hardwick R, Huntsman D, Carneiro F, Guilford P, Blair V, et al: Hereditary diffuse gastric cancer: updated consensus guidelines for clinical management and directions for future research. J Med Genet 2010; 47:436-444.

29 Gylling A, Abdel-Rahman WM, Juhola M, Nuorva K, Hautala E, Järvinen HJ, et al: Is gastric cancer part of the tumour spectrum of hereditary non-polyposis colorectal cancer? A molecular genetic study. Gut 2007;56:926933.

30 Lengauer C, Kinzler KW, Vogelstein B: Genetic instabilities in human cancers. Nature 1998;396:643-649.

-31 Belien JA, Buffart TE, Gill AJ, Broeckaert MA, Quirke P, Meijer GA, et al: Gross genomic damage measured by DNA image cytometry independently predicts gastric cancer patient survival. Br J Cancer 2009;101:1011-1018.

32 Perucho M: Microsatellite instability: the mutator that mutates the other mutator. Nat Med 1996;2:630-631.

33 Oue N, Oshimo Y, Nakayama H, Ito R, Yoshida K, Matsusaki K, et al: DNA methylation of multiple genes in gastric carcinoma: association with histological type and $\mathrm{CpG}$ island methylator phenotype. Cancer Sci 2003;94: 901-905.
34 Lee JH, Park SJ, Abraham SC, Seo JS, Nam JH, Choi C, et al: Frequent CpG island methylation in precursor lesions and early gastric adenocarcinomas. Oncogene 2004;23:46464654.

-35 Oliveira C, Seruca R, Seixas M, Sobrinho-Simoes M: The clinicopathological features of gastric carcinomas with microsatellite instability may be mediated by mutations of different 'target genes': a study of the TGFbeta RII, IGFII R, and BAX genes. Am J Pathol 1998; 153:1211-1219.

36 Hayden JD, Martin IG, Cawkwell L, Quirke P: The role of microsatellite instability in gastric carcinoma. Gut 1998;42:300-303.

37 Wirtz HC, Mueller W, Noguchi T, Scheven M, Rueschoff J, Hommel G, et al: Prognostic value and clinicopathological profile of microsatellite instability in gastric cancer. Clin Cancer Res 1998;4:1749-1754.

38 Vauhkonen M, Vauhkonen H, Sajantila A, Sipponen P: Differences in genomic instability between intestinal- and diffuse-type gastric cancer. Gastric Cancer 2005;8:238-244.

-39 Hayden JD, Cawkwell L, Dixon MF, Pardal F, Murgatroyd H, Gray S, et al: A comparison of microsatellite instability in early onset gastric carcinomas from relatively low and high incidence European populations. Int J Cancer 2000;85:189-191.

$40 \mathrm{Kim}$ H, An JY, Noh SH, Shin SK, Lee YC, Kim $\mathrm{H}$ : High microsatellite instability predicts good prognosis in intestinal-type gastric cancers. J Gastroenterol Hepatol 2011;26:585592.

41 Fleisher AS, Esteller M, Wang S, Tamura G, Suzuki H, Yin J, et al: Hypermethylation of the hMLH1 gene promoter in human gastric cancers with microsatellite instability. Cancer Res 1999;59:1090-1095.

42 Grabsch H, Kerr D, Quirke P: Is there a case for routine clinical application of ploidy measurements in gastrointestinal tumours? Histopathol 2004;45:312-334.

43 Knuutila S, Bjorkqvist AM, Autio K, Tarkkanen M, Wolf M, Monni O, et al: DNA copy number amplifications in human neoplasms: review of comparative genomic hybridization studies. Am J Pathol 1998;152:1107-1123.

44 Myllykangas S, Junnila S, Kokkola A, Autio $\mathrm{R}$, Scheinin I, Kiviluoto $\mathrm{T}$, et al: Integrated gene copy number and expression microarray analysis of gastric cancer highlights potential target genes. Int J Cancer 2008; 123 : 817-825.

45 Vauhkonen H, Vauhkonen M, Sajantila A, Sipponen P, Knuutila S: Characterizing genetically stable and unstable gastric cancers by microsatellites and array comparative genomic hybridization. Cancer Genet Cytogenet 2006;170:133-139.

46 Buffart TE, van Grieken NC, Tijssen M, Coffa J, Ylstra B, Grabsch HI, et al: High resolution analysis of DNA copy-number aberrations of chromosomes 8,13 , and 20 in gastric cancers. Virchows Arch 2009;455:213-223. 
-47 Furuya T, Uchiyama T, Adachi A, Okada T, Nakao M, Oga A, et al: The development of a mini-array for estimating the disease state of gastric adenocarcinoma by array CGH. BMC Cancer 2008;8:393.

-48 Liu XP, Li DY, Liu XL, Xu JD, Furuya T, Kawauchi S, et al: Comparison of chromosomal aberrations between primary tumors and their synchronous lymph-node metastases in intestinal-type gastric carcinoma. Pathol Res Pract 2009;205:105-111.

-49 Buffart TE, Carvalho B, Hopmans E, Brehm V, Kranenbarg EK, Schaaij-Visser TB, et al: Gastric cancers in young and elderly patients show different genomic profiles. J Pathol 2007;211:45-51.

-50 Buffart TE, Louw M, van Grieken NC, Tijssen M, Carvalho B, Ylstra B, et al: Gastric cancers of Western European and African patients show different patterns of genomic instability. BMC Med Genomics 2011;4:7.

-51 Weiss MM, Kuipers EJ, Postma C, Snijders AM, Pinkel D, Meuwissen SG, et al: Genomic alterations in primary gastric adenocarcinomas correlate with clinicopathological characteristics and survival. Cell Oncol 2004;26: 307-317.

-52 Tomioka N, Morita K, Kobayashi N, Tada M, Itoh T, Saitoh S, et al: Array comparative genomic hybridization analysis revealed four genomic prognostic biomarkers for primary gastric cancers. Cancer Genet Cytogenet 2010;201:6-14.

- 53 Kang JU, Kang JJ, Kwon KC, Park JW, Jeong TE, Noh SM, et al: Genetic alterations in primary gastric carcinomas correlated with clinicopathological variables by array comparative genomic hybridization. J Korean Med Sci 2006;21:656-665

- 54 French AJ, Petroni G, Thibideau SN, Smolkin M, Bissonette E, Roviello F, et al: Allelic imbalance of $8 \mathrm{p}$ indicates poor survival in gastric cancer. J Mol Diagn 2004;6:243-252.

- 55 Koo SH, Jeong TE, Kang J, Kwon KC, Park JW, Noh SM: Prognostic implications for gastric carcinoma based on loss of heterozygosity genotypes correlation with clinicopathologic variables. Cancer Genet Cytogenet 2004;153: 26-31.

- 56 Kang GH, Lee HJ, Hwang KS, Lee S, Kim JH, Kim JS: Aberrant CpG island hypermethylation of chronic gastritis, in relation to aging, gender, intestinal metaplasia, and chronic inflammation. Am J Pathol 2003;163:15511556.

57 Toyota M, Ahuja N, Suzuki H, Itoh F, OheToyota M, Imai K, et al: Aberrant methylation in gastric cancer associated with the CpG island methylator phenotype. Cancer Res 1999; 59:5438-5442.

58 Kusano M, Toyota M, Suzuki H, Akino K, Aoki F, Fujita M, et al: Genetic, epigenetic, and clinicopathologic features of gastric carcinomas with the $\mathrm{CpG}$ island methylator phenotype and an association with Epstein-Barr virus. Cancer 2006;106:1467-1479.
Korenaga D, Mori M, Okamura T, Sugimachi K, Enjoji M: DNA ploidy in clinical malignant gastric lesions less than $5 \mathrm{~mm}$ in diameter. Cancer 1986;58:2542-2545.

-60 Kamegawa T, Okamura T, Sugimachi K, Inokuchi K: Preoperative detection of a highly malignant type of early gastric carcinoma by cytophotometric DNA analysis. Jpn J Surg 1986;16:169-174.

-61 Buffart TE, Carvalho B, Mons T, Reis RM, Moutinho C, Silva P, et al: DNA copy number profiles of gastric cancer precursor lesions. BMC Genomics 2007;8:345.

62 Uchida M, Tsukamoto Y, Uchida T, Ishikawa Y, Nagai T, Hijiya N, et al: Genomic profiling of gastric carcinoma in situ and adenomas by array-based comparative genomic hybridization. J Pathol 2010;221:96-105.

63 Hamamoto T, Yokozaki H, Semba S, Yasui W, Yunotani S, Miyazaki K, et al: Altered microsatellites in incomplete-type intestinal metaplasia adjacent to primary gastric cancers. J Clin Pathol 1997;50:841-846.

64 Semba S, Yokozaki H, Yamamoto S, Yasui W, Tahara E: Microsatellite instability in precancerous lesions and adenocarcinomas of the stomach. Cancer 1996;77:1620-1627.

65 Fleisher AS, Esteller M, Tamura G, Rashid A, Stine OC, Yin J, et al: Hypermethylation of the hMLH1 gene promoter is associated with microsatellite instability in early human gastric neoplasia. Oncogene 2001;20:329-335.

-66 Kuniyasu H, Yasui W, Kitadai Y, Yokozaki H, Ito $\mathrm{H}$, Tahara E: Frequent amplification of the c-met gene in scirrhous type stomach cancer. Biochem Biophys Res Commun 1992;189: 227-232.

67 Kuniyasu H, Yasui W, Yokozaki H, Kitadai Y, Tahara E: Aberrant expression of c-met mRNA in human gastric carcinomas. Int $\mathrm{J}$ Cancer 1993;55:72-75.

68 Lee J, Seo JW, Jun HJ, Ki CS, Park SH, Park YS, et al: Impact of MET amplification on gastric cancer: possible roles as a novel prognostic marker and a potential therapeutic target. Oncol Rep 2011;25:1517-1524.

69 Toyokawa T, Yashiro M, Hirakawa K: Co-expression of keratinocyte growth factor and $\mathrm{K}$ sam is an independent prognostic factor in gastric carcinoma. Oncol Rep 2009;21:875880.

70 Hattori Y, Itoh $\mathrm{H}$, Uchino S, Hosokawa K, Ochiai A, Ino Y, et al: Immunohistochemical detection of $\mathrm{K}$-sam protein in stomach cancer. Clin Cancer Res 1996;2:1373-1381.

71 Sakamoto H, Mori M, Taira M, Yoshida T, Matsukawa S, Shimizu K, et al: Transforming gene from human stomach cancers and a noncancerous portion of stomach mucosa. Proc Natl Acad Sci USA 1986;83:3997-4001.

2 Tsujino T, Yoshida K, Nakayama H, Ito H, Shimosato T, Tahara E: Alterations of oncogenes in metastatic tumours of human gastric carcinomas. Br J Cancer 1990;62:226-230.
73 Ueki T, Koji T, Tamiya S, Nakane PK, Tsuneyoshi M: Expression of basic fibroblast growth factor and fibroblast growth factor receptor in advanced gastric carcinoma. J Pathol 1995;177:353-361.

74 Gravalos C, Jimeno A: HER2 in gastric cancer: a new prognostic factor and a novel therapeutic target. Ann Oncol 2008;19:15231529.

75 Grabsch H, Sivakumar S, Gray S, Gabbert HE, Muller W: HER2 expression in gastric cancer: rare, heterogeneous and of no prognostic value - conclusions from 924 cases of two independent series. Cell Oncol 2010;32:57-65.

-76 Okines AF, Thompson LC, Cunningham D, Wotherspoon A, Reis-Filho JS, Langley RE, et al: Effect of HER2 on prognosis and benefit from peri-operative chemotherapy in early oesophago-gastric adenocarcinoma in the MAGIC trial. Ann Oncol 2013;24:1253-1261.

-77 Bang YJ, Van Cutsem E, Feyereislova A, Chung HC, Shen L, Sawaki A, et al: Trastuzumab in combination with chemotherapy versus chemotherapy alone for treatment of HER2-positive advanced gastric or gastro-oesophageal junction cancer (ToGA): a phase 3 , open-label, randomised controlled trial. Lancet 2010;376:687-697.

78 Lee KH, Lee JS, Suh C, Kim SW, Kim SB, Lee $\mathrm{JH}$, et al: Clinicopathologic significance of the $\mathrm{K}$-ras gene codon 12 point mutation in stomach cancer. An analysis of 140 cases. Cancer 1995;75:2794-2801.

79 Corso G, Velho S, Paredes J, Pedrazzani C, Martins D, Milanezi F, et al: Oncogenic mutations in gastric cancer with microsatellite instability. Eur J Cancer 2011;47:443-451.

80 Wu M, Semba S, Oue N, Ikehara N, Yasui W, Yokozaki H: BRAF/K-ras mutation, microsatellite instability, and promoter hypermethylation of hMLH1/MGMT in human gastric carcinomas. Gastric Cancer 2004;7:246-253.

81 Tohdo H, Yokozaki H, Haruma K, Kajiyama G, Tahara E: p53 gene mutations in gastric adenomas. Virchows Arch 1993;63:191-195.

82 Sakurai S, Sano T, Nakajima T: Clinicopathological and molecular biological studies of gastric adenomas with special reference to p53 abnormality. Pathol Int 1995;45:51-57.

$\checkmark 83$ Ochiai A, Yamauchi Y, Hirohashi S: p53 mutations in the non-neoplastic mucosa of the human stomach showing intestinal metaplasia. Int J Cancer 1996;69:28-33.

84 Horii A, Nakatsuru S, Miyoshi Y, Ichii S, Nagase $\mathrm{H}$, Kato $\mathrm{Y}$, et al: The APC gene, responsible for familial adenomatous polyposis, is mutated in human gastric cancer. Cancer Res 1992;52:3231-3233.

-85 Nishimura K, Yokozaki H, Haruma K, Kajiyama G, Tahara E: Alterations of the apc gene in carcinoma cell-lines and precancerous lesions of the stomach. Int J Oncol 1995;7:587-592.

-86 Hsu PI, Hsieh HL, Lee J, Lin LF, Chen HC, Lu PJ, et al: Loss of RUNX3 expression correlates with differentiation, nodal metastasis, and poor prognosis of gastric cancer. Ann Surg Oncol 2009;16:1686-1694.
Gastric Cancer Pathology and Underlying Molecular Mechanisms
Dig Surg 2013;30:150-158 DOI: $10.1159 / 000350876$ 
-87 Kim TY, Lee HJ, Hwang KS, Lee M, Kim JW, Bang YJ, et al: Methylation of RUNX3 in various types of human cancers and premalignant stages of gastric carcinoma. Lab Invest 2004;84:479-484.

88 Zang ZJ, Cutcutache I, Poon SL, Zhang SL, McPherson JR, Tao J, et al: Exome sequencing of gastric adenocarcinoma identifies recurrent somatic mutations in cell adhesion and chromatin remodeling genes. Nat Genet 2012;44:570-574.
89 Wu Y, Grabsch H, Ivanova T, Tan IB, Murray $\mathrm{J}$, Ooi CH, et al: Comprehensive genomic meta-analysis identifies intra-tumoural stroma as a predictor of survival in patients with gastric cancer. Gut 2012, E-pub ahead of print.

90 Dulak AM, Schumacher S, van Lieshout J, Imamura Y, Fox C, Shim B, et al: Gastrointestinal adenocarcinomas of the esophagus, stomach and colon exhibit distinct patterns of genome instability and oncogenesis. Cancer Res 2012;72:4383-4393.

91 Kong YW, Ferland-McCollough D, Jackson TJ, Bushell M: microRNAs in cancer management. Lancet Oncol 2012;13:e249-e258.
92 Wang F, Sun GP, Zou YF, Hao JQ, Zhong F, Ren WJ: MicroRNAs as promising biomarkers for gastric cancer. Cancer Biomark 2012; 11:259-267.

93 Yin Y, Li J, Chen S, Zhou T, Si J: MicroRNAs as diagnostic biomarkers in gastric cancer. Int J Mol Sci 2012;13:12544-12555.

94 Carl-McGrath S, Ebert M, Röcken C: Gastric adenocarcinoma: epidemiology, pathology and pathogenesis. Cancer Ther 2007;5:877894. 